\title{
Occurrence and Pathogenicity of Fungi Associated with Melon Root Rot and Vine Decline in California
}

\author{
B. J. Aegerter, T. R. Gordon, and R. M. Davis, Department of Plant Pathology, University of California, Davis \\ 95616
}

\begin{abstract}
Aegerter, B. J., Gordon, T. R., and Davis, R. M. 2000. Occurrence and pathogenicity of fungi associated with melon root rot and vine decline in California. Plant Dis. 84:224-230.

The occurrence of fungi associated with root rot and vine decline of melon (Cucumis melo) in commercial fields in California was surveyed over 3 years. The fungi most frequently isolated from discolored vascular tissue or root rot were Acremonium cucurbitacearum, Rhizopycnis vagum, Monosporascus cannonballus, Fusarium solani, Macrophomina phaseolina, Pythium spp., and Verticillium dahliae. The frequency of isolation of the various fungi varied with root symptomology. Pythium spp., and M. phaseolina were frequently associated with a wet, brownish root rot, while A. cucurbitacearum, R. vagum, and Rhizoctonia solani were generally associated with a dry, corky root rot. Presence of Monosporascus cannonballus was associated both with a wet, brownish rot as well as with discrete, reddish, corky lesions. The frequency of isolation of a given pathogen varied with geographic location, with $M$. cannonballus present only in the southern production areas, while A. cucurbitacearum and Rhizopycnis vagum were most common in the northern production areas. In pathogenicity tests in field microplots, $M$. cannonballus caused vine collapse and severe root rot of cantaloupe, reducing root length density by $93 \%$. California isolates of $R$. vagum and A. cucurbitacearum, although only weakly pathogenic in field microplots, caused root discoloration and reduced vine growth in greenhouse tests. Reduction in dry weight of greenhouse-grown cantaloupe was 40, 23, and 39\% for $R$. vagum, A. cucurbitacearum, and $M$. cannonballus, respectively.
\end{abstract}

Approximately 37,500 ha of cantaloupe and honeydew (Cucumis melo var. reticulatus and var. inodorus) were planted in California in 1999, representing $68 \%$ of the U.S. national production (7). A root rot and associated vine decline have been continuing problems on many types of melons, including cantaloupe, honeydew, various mixed melons, and watermelon (Citrullus lanatus). Aboveground symptoms include yellowing and death of the crown leaves. Sometimes, only scant or no evidence of root rot is apparent but, in most cases, root symptoms include a rot of secondary and feeder roots and reddish or corky lesions on the taproot. Although root vascular tissue is sometimes discolored, this rarely extends into the stem. Vine collapse typically occurs just prior to harvest, resulting in premature fruit ripening, low sugar accumulation, and exposure of fruit to the sun.

Corresponding author: B. J. Aegerter

E-mail: bjaegerter@ucdavis.edu

This work was supported in part by a grant from the California Melon Research Board.

Accepted for publication 19 November 1999.

Publication no. D-2000-0121-01R

(C) 2000 The American Phytopathological Society
A number of fungi have been reported as causal agents of melon collapse worldwide, but descriptions of vine and root symptoms have often been overlapping and the cause of vine collapse in many cases is unclear. In 1970, Troutman and Matejka (25) concluded that Rhizoctonia solani, Verticillium albo-atrum, and an unidentified fungus which was later described as a genus et species novus, Monosporascus cannonballus (20), were the primary fungi associated with cantaloupe root rots in Arizona. In Texas, a root rot-vine decline of muskmelon was first reported in 1988 (8) and was subsequently attributed to $M$. cannonballus (15). M. cannonballus has also been reported from California (5). A sudden wilt of melons in California has been attributed to Pythium ultimum, $P$. aphanidermatum, and $P$. myriotylum $(3,12,13)$. In Spain, Acremonium cucurbitacearum was the most commonly isolated fungus from muskmelons suffering from "sudden death" on the eastern Mediterranean coast (10). A. cucurbitacearum has also been associated with vine decline in parts of the Central Valley of California (5). A Stagonospora sp.-like fungus has been implicated in vine decline in the Rio Grande Valley of Texas (16) and was recently described as a genus et species novus, Rhizopycnis vagum (9). A corky root rot of melons in France is caused by $P y$ renochaeta lycopersici (22).

The objective of this work was to survey melon fields in California for the occurrence of root-infecting fungi and to test their pathogenicities under field and greenhouse conditions. In addition, symptomology associated with root colonization by these fungi is described.

\section{MATERIAL AND METHODS}

Disease survey. To determine the occurrence of fungi associated with melon roots, samples of cantaloupe, honeydew, and occasionally mixed melon and watermelon roots were obtained over a 3-year period (1995 to 1997) from fields in 11 counties in California. In 1995, samples were obtained from 30 fields where plants suffered from wilt, premature vine decline, or root rot. In 1996, samples were obtained from symptomatic plants in 27 fields. Soil samples were also obtained from 23 fields in 1996. Samples were composites of 15 to 30 cores taken from the surface soil to 15 cm deep. In 1997, roots from 24 fields were sampled.

To remove soil, the root systems were washed in 1 liter of $1 \%$ sodium metaphosphate on a shaker for 15 to $20 \mathrm{~min}$. After symptoms were noted, isolations were made from cortex and vasculature of the tap root, secondary and tertiary roots, the hypocotyl, and stem vascular tissue of four to six plants from each field, regardless of whether the specific tissue was symptomatic. The pieces of root tissue were surface sterilized in $0.525 \%$ sodium hypochlorite for $2 \mathrm{~min}$ and plated on $1.5 \%$ water agar amended with $100 \mathrm{ppm}$ streptomycin sulfate (SWA). When symptoms were typical of pythiaceous fungi (a wet, brownish decay; 12), symptomatic tissue pieces also were plated on a selective medium consisting of corn meal agar (Difco Laboratories, Detroit) amended with $10 \mathrm{ppm}$ pimaricin, $250 \mathrm{ppm}$ ampicillin, $10 \mathrm{ppm}$ rifampicin, and $25 \mathrm{ppm}$ pentachloronitrobenzene. Some tissue pieces were placed in a moist chamber for 7 to 10 days to allow development of pycnidia or perithecia.

After the plates were incubated at room temperature for 3 to 5 days, hyphal tips or spores of various fungi were transferred to 
potato dextrose agar (PDA, Difco Laboratories) or $20 \%$ V8 agar for identification. Fusarium spp. were identified based on morphological characteristics on carnation leaf agar (17). The frequency of isolation of each fungus from tissue types and field locations was recorded.

Ascospores of $M$. cannonballus were extracted from the field soil samples by a method adapted from Stanghellini and Rasmussen (24). After the entire sample was sifted through a 4-mm screen, four 20$\mathrm{g}$ subsamples were each added to $200 \mathrm{ml}$ of water and stirred for 5 min using a magnetic stirrer. Each subsample was then washed through nested 75- and 38- $\mu \mathrm{m}$ sieves for $5 \mathrm{~min}$. The material retained by the $75-\mu \mathrm{m}$ sieve was discarded while that retained on the $38-\mu \mathrm{m}$ sieve was centrifuged at $4,000 \mathrm{rpm}(2,500 \times g)$ for $2 \mathrm{~min}$ in $40 \mathrm{ml}$ of $75 \%$ sucrose. The supernatant was decanted onto the 38- $\mu \mathrm{m}$ sieve and rinsed with water. The material retained on the sieve was stored in a small quantity of water at $4^{\circ} \mathrm{C}$ until it was analyzed. In this way, material of roughly the same size and density as $M$. cannonballus ascospores was separated from most of the other soil and organic matter. Spores in the water were enumerated under a stereomicroscope at a magnification of $40 \times$ in a petri dish imprinted with a roughly $1-\mathrm{cm}^{2}$ grid. Spores were counted if they were shiny black, entirely smooth, and 35 to $50 \mu \mathrm{m}$ in diameter. The four subsample values from each composite sample were averaged. These were composite samples; therefore, the variation between subsamples was due to the extraction method and not to variation across the field. Hence, statistical comparisons of spore counts between fields could not be made.

Inoculum production. All isolates used in pathogenicity tests were obtained from symptomatic melon roots in California.
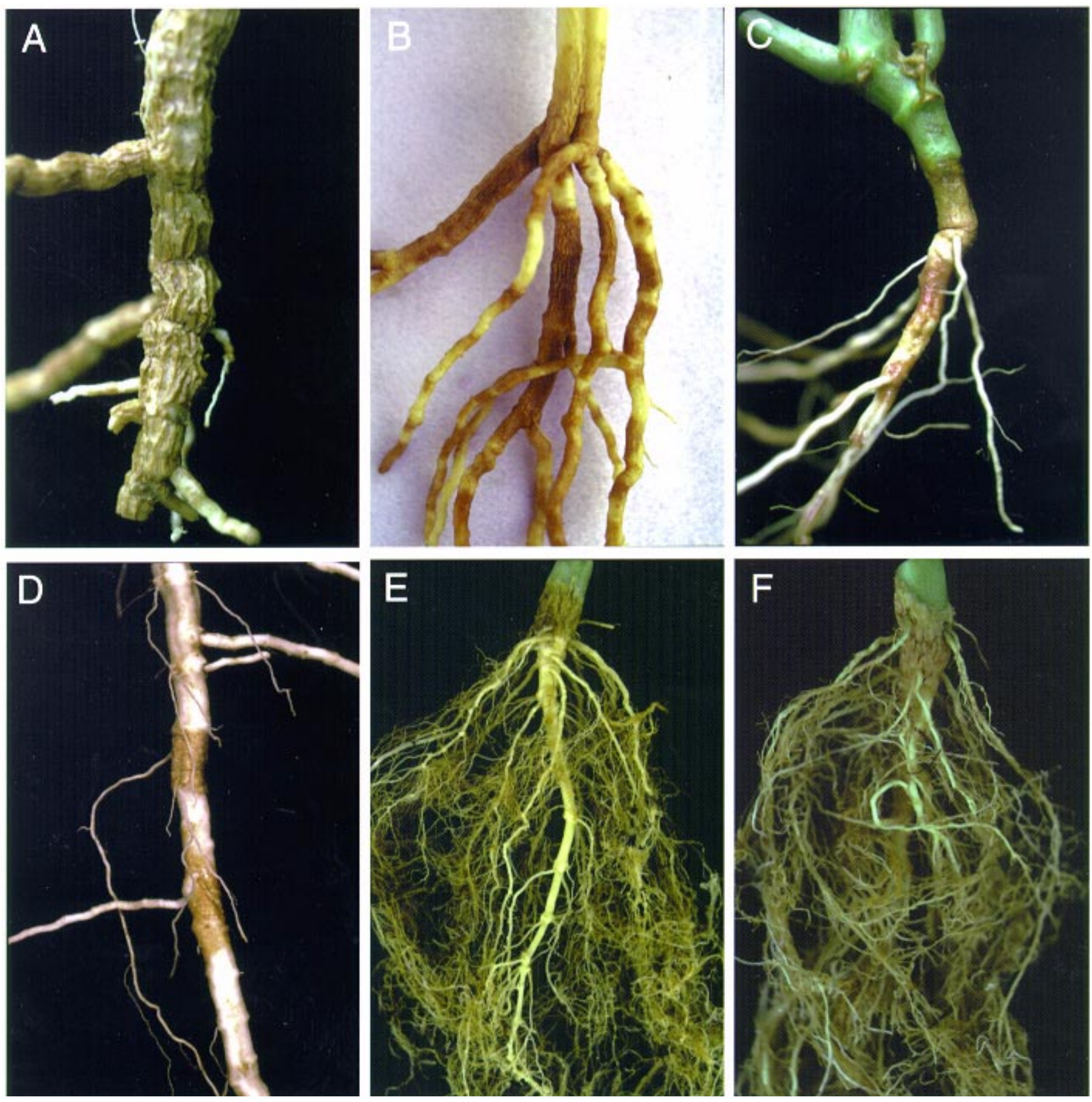

Fig. 1. Symptoms associated with (A and B) Acremonium cucurbitacearum and (C) Rhizopycnis vagum in diseased commercial fields. Symptoms caused by A. cucurbitacearum on cantaloupe inoculated in (D) field microplots and (E) the greenhouse. (F) Symptoms caused by Rhizopycnis vagum on cantaloupe inoculated in the greenhouse. 
Single-spore isolates of A. cucurbitacearum and Fusarium spp. were obtained prior to use in pathogenicity tests, while hyphal tip isolates of $R$. vagum and $M$. cannonballus were used. Inoculum for field and greenhouse trials was grown on a mixture of washed quartz sand and ground oat hulls (Quaker Oats, Chicago), combined at a rate of $45 \mathrm{~g}$ of oat hulls to 500 $\mathrm{cm}^{3}$ of sand. In 1-liter flasks, $100 \mathrm{ml}$ of water was combined with $500 \mathrm{~cm}^{3}$ of this medium and autoclaved twice for $60 \mathrm{~min}$ with a 1-day interval. The medium was inoculated with two to three $1-\mathrm{cm}^{2}$ pieces of colonized agar cut from a PDA culture. The flasks were incubated at room temperature under $12 \mathrm{~h}$ of fluorescent light per day. After the hyphae had grown out 2 to 3 $\mathrm{cm}$, the flasks were shaken to distribute the mycelium. Colonization of the substrate was completed in 5 to 7 weeks. In one field trial (1995), inoculum of A. cucurbitacearum and $M$. cannonballus was grown in a similar manner on sterilized millet. Microsclerotial inoculum of $V$. dahliae was prepared by growing the fungus in liquid culture which was then spread on sheets of sterile cellophane overlying Puhalla's minimal agar medium (21) in trays (33 by $53 \mathrm{~cm}$ ). After 2 to 3 weeks, the cellophane was removed, homogenized in a blender with water, and combined with sand.

The CFU concentration of the colonized sand and oat-hull substrate was determined by serial dilution. Once the flasks of inoculum had been bulked, two or three 1gm samples each were added to $99 \mathrm{ml}$ of $0.2 \%$ water agar (WA) and mixed with a magnetic stirrer for $10 \mathrm{~min}$ to prepare a 100 -fold dilution. The $10^{3}$ to $10^{6}$ dilutions were prepared by adding $1 \mathrm{ml}$ of the previous dilution to $9 \mathrm{ml}$ of $0.2 \%$ WA. Three 1$\mathrm{ml}$ subsamples of each dilution were plated on PDA and incubated at room temperature for 3 days. The number of colonies per plate was multiplied by the dilution factor to obtain the $\mathrm{CFU} / \mathrm{g}$ of inoculum on a moist-weight basis. The counts obtained from the three subsample plates, the various dilutions, and the two or three samples were averaged. CFU concentrations utilized in pathogenicity testing were determined by preliminary experiments or adapted from reports in the literature (6).

Field pathogenicity tests. In 1995, 1996, and 1997, field microplots were created by digging a trench into which plastic cylinders $(75 \mathrm{~cm}$ in diameter) were placed; soil was filled back in around and within the cylinders so the bottom of the plots was roughly $46 \mathrm{~cm}$ below the soil level. Newly constructed microplots were used each year. In some treatments, $43 \mathrm{ml}$ of metam-sodium was added to water in each of the plots at a rate equivalent to 935 liters/ha of metam-sodium. After at least 3 weeks, inoculum was mixed into the upper $15 \mathrm{~cm}$ of the treated plots, while the control plots remained untreated. Plots were direct seeded with the cantaloupe cv. Mag- num .45 and thinned to four plants/plot. All plots were covered with finely meshed nylon row covers to protect the young plants from virus vectors until flowering and vining. All plots were fertilized once at thinning with ammonium sulfate at a rate of $168 \mathrm{~kg}$ of N/ha and watered by dripirrigation or hand watering as needed. The crop was grown to horticultural maturity (80 to 90 days after seeding).

In 1995, two experiments were conducted in the field microplots. In the first experiment, planted in June, the soil was not treated with metam-sodium. Plots were inoculated with $M$. cannonballus $(3.6 \mathrm{~kg}$ of colonized millet/plot), A. cucurbitacearum (3.6 kg of colonized millet/plot), or nothing. In the second experiment, planted in July, all plots received the metam-sodium treatment and were inoculated as above with $M$. cannonballus, A. cucurbitacearum, V. dahliae, or non-colonized millet. No measurements of CFU concentrations of the inoculum were made. In both experiments, each treatment was replicated four times in a randomized complete block design. In an experiment planted in July 1996, plots were inoculated with A. cucurbitacearum $(1.5 \mathrm{~kg}$ of colonized sand-oat mixture/plot, 17,000 CFU/g soil), $M$. cannonballus $(0.75 \mathrm{~kg}$ of colonized sand-oat mixture/plot, unknown CFU concentration), F. solani (1 kg of colonized sand-oat mixture/plot, 5,500 CFU/g soil), $R$. vagum (1.3 kg of colonized sand-oat mixture/plot, unknown CFU concentration), or nothing. Each inoculation treatment included three plots that had been treated with metamsodium prior to planting and three that had not. In a second experiment, also planted in July, plots were treated with metam-sodium and then inoculated (at same rates as above) with A. cucurbitacearum, M. cannonballus, or nothing, and all plots were watered with about half the frequency of plots in the first experiment. In all experiments, each treatment was replicated three times in a randomized complete block design.

In 1997, plots were inoculated with $M$. cannonballus $(2.4 \mathrm{~kg} / \mathrm{plot}, 400 \mathrm{CFU} / \mathrm{g}$ soil), A. cucurbitacearum (2.8 kg/plot, $3,000 \mathrm{CFU} / \mathrm{g}$ soil), R. vagum (3.5 kg/plot, $6,500 \mathrm{CFU} / \mathrm{g}$ soil), or nothing. All plots were treated with metam-sodium prior to planting in June. All treatments were replicated three times in a completely randomized design.

In all experiments, plants were harvested when the fruit was mature. Roots and lower stems were gently removed from the plots, washed in $1 \%$ sodium metaphosphate, photographed, and rated for disease severity on the following scale: $0=$ no symptoms; 1 = few lesions (covering $<10 \%$ of root), secondary root rot slight; 2 $=$ rot of secondary roots or lesions covering approximately $25 \%$ of the root; $3=$ lesions covering at least $50 \%$ of the root and dead secondary roots; and $4=$ general root rot, most of the root affected. Representative symptomatic tissues were surface-sterilized for $2 \mathrm{~min}$ in $0.525 \%$ sodium hypochlorite and plated on SWA.

In 1997, estimation of root density in each treatment at the end of the season was conducted by a method adapted from Ward et al. (26). A core ( $2 \mathrm{~cm}$ in diameter) from the surface to $20 \mathrm{~cm}$ in depth was collected about $3 \mathrm{~cm}$ from the crown of each of the four plants in each plot. The four cores from each plot were combined and added to $300 \mathrm{ml}$ of water. After the water was swirled and large soil particles were allowed to settle, the water was decanted through a $250-\mu \mathrm{m}$ sieve. This process of adding water, allowing large soil particles to settle, and decanting was repeated twice. In this way, the organic matter (larger than $250 \mu \mathrm{m})$ in the sample was separated from most of the soil particles. The organic matter was then added to water several millimeters deep in a clear plastic tray (13 by $18 \mathrm{~cm}$ ) overlaying a $1-\mathrm{cm}$ grid. Intersections of the grid lines with live roots visible to the naked eye were counted. Estimation of root length was made using the equation of Newman (18). To assess the accuracy of this estimation, a thread (55 cm long) was spread on the tray and its intersections with the grid lines counted. Whether the thread was entire or cut into sections ( 1 to $2 \mathrm{~cm}$ long), the equation provided an approximation of its length within about $\pm 0.9 \%$.

Greenhouse pathogenicity tests. The pathogenicities of $R$. vagum, A. cucurbitacearum, and $M$. cannonballus were evaluated in separate experiments in the greenhouse. The fungi were tested on watermelon (C. lanatus cv. Crimson Sweet), honeydew (C. melo var. inodorus cv. Green Flesh), squash (Cucurbita pepo cv. Super Set), and cantaloupe (C. melo var. reticulatus cvs. Magnum .45 [F1 hybrid] and Top Net [open pollinated]). The experiments were conducted in 3.8-liter pots filled with potting mix (40\% washed sand, $20 \%$ nitrified redwood, $20 \%$ sphagnum peat moss, $20 \%$ pumice rock, and a trace of lime) and sterilized Yolo sandy loam combined 50:50 on a volumetric basis $(2.5$ $\mathrm{kg}$ of mixture/pot). Inoculum was mixed with the medium at $5,000 \mathrm{CFU} / \mathrm{g}$ of soil for $R$. vagum, 20,000 CFU/g for A. cucurbitacearum, and $30 \mathrm{CFU} / \mathrm{g}$ for $M$. cannonballus. The plants were direct seeded, thinned to two plants per pot, fertilized once with $4 \mathrm{~g}$ of a slow-release fertilizer (Apex 21-5-6 plus micronutrients, J. R. Simplot Co., Boise, ID), and watered as needed. In all greenhouse experiments, the temperature ranged from a minimum of $20^{\circ} \mathrm{C}$ to a maximum of $27^{\circ} \mathrm{C}$ (winter) or $33^{\circ} \mathrm{C}$ (summer). Plants were harvested at 40 days (A. cucurbitacearum experiments) or 50 days ( $R$. vagum and M. cannonballus experiments) after seeding. Each experiment was repeated once.

At harvest, the length of the main shoots was measured and roots were recovered by 
gentle washing of the root ball from the pot. Roots were rated for disease severity based on the following scale: $0=$ no symptoms, $1=$ slight or limited area of discoloration, 2 = general discoloration (one or two lesions), 3 = general discoloration (rot of some tissues), and $4=$ rot of entire tap and feeder roots. A small piece of representative root tissue was plated on SWA to isolate fungi. Weights were measured after the tissue was dried in an oven at $50^{\circ} \mathrm{C}$ for 2 to 3 days.

Statistical analyses. Analysis of variance was used to evaluate differences in shoot length, dry weight, and disease severity in greenhouse experiments and differences in root density and disease severity in microplot experiments. Measurements were transformed to their natural log equivalents, when necessary, to eliminate heteroscedasticity. Mean separations were determined using Fisher's least significant difference $(P=0.05)$. Statistical computations were performed using the PROC GLM procedure in SAS (version 6; SAS Institute, Cary, NC).

\section{RESULTS}

Disease survey. A. cucurbitacearum, which was recovered from plants in $32 \%$ of the surveyed fields, and R. vagum (31\%) were the fungi most commonly isolated from symptomatic melon roots over a 3year period. Other commonly isolated fungi included Pythium spp. (23\%), Macrophomina phaseolina (23\%), V. dahliae (25\%), F. solani (21\%), Monosporascus cannonballus (15\%), and Rhizoctonia solani $(7 \%)$. F. oxysporum and $F$. equiseti were infrequently isolated. $M$. cannonballus was found frequently in the southern San Joaquin Valley and in the Imperial Valley, less frequently in the upper San Joaquin Valley, and never in the Sacramento Valley. In contrast, A. cucurbitacearum was isolated only once in the Imperial Valley and frequently in the central and northern production areas of the San Joaquin and Sacramento Valleys. The incidence of $V$. dahliae was concentrated in the production areas of Fresno and Merced Counties, occurring only rarely outside these areas. The other fungi exhibited a more general distribution.

Distinct symptoms often were associated with specific fungi. For example, A. cu- curbitacearum was associated with yellowish or brownish corky lesions, which often formed discrete transverse bands on the tap and secondary roots (Table 1, Fig. $1 \mathrm{~A}$ and B). Rhizopycnis vagum also was isolated occasionally from these lesions. Pycnidia of $R$. vagum were found occasionally on symptomatic roots that were incubated in a moist chamber. $R$. vagum also was isolated from pinkish, sunken lesions on the crown of the vine (Fig. 1C), and from generally discolored or rotten roots (Table 1). M. cannonballus was associated with reddish-brown lesions of the tap and secondary roots and necrosis of secondary and tertiary roots. Perithecia of M. cannonballus often were observed on such tertiary roots. Macrophomina phaseolina was associated with a wet, darkly discolored rot of the secondary and tap roots and with crown lesions, where microsclerotia, characteristic of this fungus, were embedded in the diseased tissue. $V$. dahliae was isolated from stem vascular tissue that was lightly discolored. Tissues exhibiting a brownish, wet decay or dark discoloration were plated on the selective medium and often yielded Pythium spp. F. solani was associated with the discrete reddish lesions, as well as with corky lesions, but these symptoms were not reproduced in subsequent pathogenicity tests (data not presented). F. equiseti was isolated from roots with various symptoms, as well as from asymptomatic tissues, but all $F$. equiseti isolates were non-pathogenic to cantaloupe (data not presented).

An average of 1.4 ascospores/g of soil characteristic of $M$. cannonballus were

Table 2. Effect of fungi on cantaloupe root health, 1997 field microplot trial ${ }^{\mathrm{w}}$

\begin{tabular}{|c|c|c|}
\hline Fungus $^{x}$ & Root disease index ${ }^{y}$ & Root density $\left(\mathrm{cm} / \mathrm{cm}^{3}\right)$ \\
\hline Monosporascus cannonballus & $2.9 \mathrm{a}$ & $0.07 \mathrm{~b}$ \\
\hline Acremonium сисurbitacearum & $0.8 \mathrm{~b}$ & $0.45 \mathrm{ab}$ \\
\hline Rhizopycnis vagum & $0.4 \mathrm{~b}$ & $1.05 \mathrm{a}$ \\
\hline None & $\ldots^{\mathrm{z}}$ & $1.00 \mathrm{a}$ \\
\hline
\end{tabular}

w Means in each column followed by the same letter are not significantly different $(P \leq 0.05)$ according to Fisher's least significant difference test. Values are means of three observations in one trial; results of two other trials were similar.

${ }^{\mathrm{x}}$ Inoculum levels in CFU/g of soil: 400 for M. cannonballus, 3,000 for A. cucurbitacearum, and 6,500 for $R$. vagum.

y $0=$ no symptoms; 1 = few lesions (covering $<10 \%$ of root), secondary root rot slight; 2 = rot of secondary roots or lesions covering approximately $25 \%$ of the root; $3=$ lesions covering at least $50 \%$ of the root, dead secondary roots; and $4=$ general root rot, most of the root affected.

${ }^{\mathrm{z}}$ No disease observed on roots grown in non-infested soil; not included in analysis.

Table 1. Frequency of isolation of various fungi from melon roots collected from 81 fields over a 3 -year period ${ }^{z}$

\begin{tabular}{|c|c|c|c|c|c|c|c|c|c|}
\hline Root tissue and symptoms & $\begin{array}{c}\text { Rhizop. } \\
\text { vagum }\end{array}$ & $\underset{\text { cucurb. }}{\text { A. }}$ & $\begin{array}{l}\text { Monosp. } \\
\text { cannon. }\end{array}$ & $\begin{array}{c}V . \\
\text { dahliae }\end{array}$ & $\begin{array}{l}\text { Pythium } \\
\text { spp. }\end{array}$ & $\begin{array}{l}\text { Macro. } \\
\text { phaseo. }\end{array}$ & R. solani & F. solani & Total \\
\hline Light brown tap or secondary root & 3 & 21 & 0 & 0 & 1 & 3 & 2 & 4 & 34 \\
\hline Brown to dark brown tap or secondary root & 5 & 14 & 1 & 0 & 6 & 8 & 3 & 1 & 38 \\
\hline Soft, watery rot of any part of root system & 6 & 5 & 6 & 0 & 12 & 10 & 1 & 2 & 42 \\
\hline Discrete, red lesions on tap and secondary root & 5 & 5 & 11 & 0 & 1 & 2 & 0 & 8 & 32 \\
\hline Corky lesions/Banding on tap and secondary root & 28 & 134 & 0 & 0 & 4 & 4 & 8 & 10 & 188 \\
\hline Discolored vasculature & 4 & 1 & 10 & 22 & 0 & 0 & 0 & 3 & 40 \\
\hline Asymptomatic root tissues & 7 & 9 & 1 & 1 & 2 & 4 & 0 & 3 & 27 \\
\hline
\end{tabular}

${ }^{\mathrm{z}}$ Fungal species, from left to right: Rhizopycnis vagum, Acremonium cucurbitacearum, Monosporascus cannonballus, Verticillium dahliae, Pythium spp., Macrophomina phaseolina, Rhizoctonia solani, Fusarium solani, total number of isolations. 
vagum reduced cantaloupe dry weight by 90\% $(P=0.0001)$ and caused root discoloration $(P=0.007$; data not presented $)$. In a subsequent experiment, a California isolate of $R$. vagum reduced dry weight of the cucurbits by an average of $19.1 \%(P=$ $0.0025)$, with significant reductions to cantaloupe (cv. Top Net) and watermelon (Fig. 2). In a replicate trial in which the plants grew less vigorously, presumably due to lower average greenhouse temperatures, dry weight of each of the five cultivars was reduced $(P=0.0001$, data not presented). In all experiments, $R$. vagum caused root discoloration and corky lesions on hypocotyl tissue (Fig. 1F), which were more severe on the melons and watermelons than on squash $(P=0.001$, Table 3$)$.

In two trials, A. cucurbitacearum reduced dry weight and shoot length of the cucurbits by an average of $11 \%(P=$ $0.0065)$ and $12 \%(P=0.0098)$, respectively. Dry weight of cantaloupe (cv. Magnum .45) and shoot length of honeydew were significantly reduced (Fig. 3). On the melons and watermelon, A. cucurbitacearum caused a general discoloration of
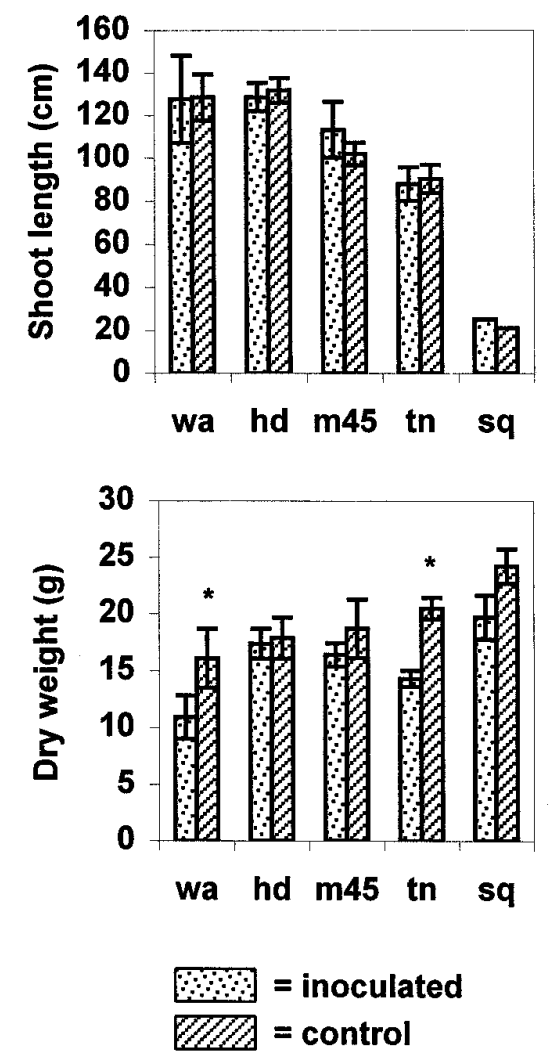

Fig. 2. Effect of Rhizopycnis vagum on shoot length and dry weight of greenhouse-grown cucurbits. Abbreviations: $\mathrm{wa}=$ watermelon $\mathrm{cv}$. Crimson Sweet, hd = honeydew cv. Green Flesh, $\mathrm{m} 45$ = cantaloupe cv. Magnum $.45, \mathrm{tn}=$ cantaloupe $\mathrm{cv}$. Top Net, and $\mathrm{sq}=$ squash $\mathrm{cv}$. Super Set. Bars indicate the standard error of the mean of four observations in one trial. Asterisks indicate differences between adjacent treatments significant at $P \leq 0.05$. the root system and a corky rot of the hypocotyl (Fig. 1E, Table 3). No disease was observed on squash or on any control plants.

In one trial, $M$. cannonballus reduced dry weight and shoot length of the cucurbits by an average of $42.3 \%(P=0.0001)$ and $42.9 \%(P=0.0001)$, respectively. Only growth of honeydew was not reduced significantly (Fig. 4). Disease symptoms included a general rot of the lateral roots and lesions on the tap root cortex. Symptoms were more severe on the melons and watermelon than on squash $(P=0.0002$, Table 3$)$. In a replicate trial, $M$. cannonballus significantly reduced the shoot length and dry weight of the inoculated plants by an average of $10 \%(P=0.031)$ and $12 \%(P=$ $0.0087)$, respectively (data not presented).

\section{DISCUSSION}

The number of pathogenic fungi capable of colonizing melon roots and the similarity of the symptoms they induce confounded diagnosis based on the appearance of roots. A few very distinctive signs, such as the microsclerotia of Macrophomina phaseolina embedded throughout diseased tissue, and the erumpent perithecia of Monosporascus cannonballus on dead secondary and tertiary roots, aided in the diagnosis of some root rots. In the absence of such signs, diagnosis necessitated observation of fungal sporulation on surface-sterilized tissue or isolation of the fungus in culture.

Several fungi were isolated from symptomatic roots of melons in California production areas, including Macrophomina phaseolina, A. cucurbitacearum, Monosporascus cannonballus, Rhizopycnis vagum, V. dahliae, F. solani, and Pythium spp. Although the frequency of isolation of a given organism varied with the symptomology, there was a substantial overlap of symptoms associated with different fungi. Frequently, more than one fungus was isolated from a single lesion or root. For example, A. cucurbitacearum and $R$. vagum were often isolated concomitantly. In their survey of four melon fields suffering vine decline in Texas, Merteley et al. isolated M. cannonballus, $F$. solani, $F$. oxysporum, a Stagonospora sp., Macrophomina phaseolina, Pythium spp., and a Cephalosporium sp., but only Monosporascus cannonballus and Macrophomina phaseolina were pathogenic to cantaloupe in greenhouse experiments (15). In Spain, A. cucurbitacearum was concluded to be the causal agent of sudden death of melons, but M. phaseolina, Rhizoctonia solani, Monosporascus eutypoides, Phytophthora spp. and Pythium spp. were also isolated (10). Of these, only A. cucurbitacearum and $R$. solani were reported as being pathogenic to melon under their test conditions (10).

Isolates of $F$. solani from cantaloupe and honeydew were nonpathogenic to melons in our greenhouse experiments and were apparently secondary colonizers of diseased tissue. Only a single isolate from rotted watermelon roots was pathogenic. Champaco et al. (8) also isolated $F$. solani from rotted root of melons in Texas, but could not demonstrate pathogenicity under greenhouse conditions $(8,15)$. F. equiseti likewise was not pathogenic in our tests, though it is known to cause disease under certain conditions (1). Both $F$. solani and $F$. equiseti are common soil saprophytes and are frequently isolated from roots (11).

$V$. dahliae was isolated from vascular tissue of declining vines and caused a collapse of inoculated plants in field microplots, but did not cause any root symptoms. $V$. dahliae was isolated most frequently in Merced County, where rotation of melons with cotton may contribute to its prevalence. In some fields, vascular colonization by $V$. dahliae may contribute to vine decline.

In our work, M. cannonballus caused severe root rot of melons in field microplots. However, M. cannonballus was isolated from diseased plants in only a few fields in our survey. Symptoms or signs of Monosporascus root rot were observed commonly in growing areas in the Imperial Valley and lower San Joaquin Valley, rarely in the upper San Joaquin Valley, and never in the Sacramento Valley. Although ascospores characteristic of $M$. cannonballus were retrieved from soils in the Sacramento Valley, it was never isolated

Table 3. Effect of various fungi on root health of greenhouse-grown cucurbits

\begin{tabular}{lccc}
\hline & \multicolumn{3}{c}{ Root disease index $^{\mathbf{y}}$} \\
\cline { 2 - 4 } Cucurbit cultivars & $\begin{array}{c}\text { Rhizopycnis } \\
\text { vagum }\end{array}$ & $\begin{array}{c}\text { Acremonium } \\
\text { cucurbitacearum }\end{array}$ & $\begin{array}{c}\text { Monosporascus } \\
\text { cannonballus }\end{array}$ \\
\hline Watermelon cv. Crimson Sweet & $2.6 \mathrm{a}$ & $1.4 \mathrm{a}$ & $2.4 \mathrm{a}$ \\
Honeydew cv. Green Flesh & $2.6 \mathrm{a}$ & $1.8 \mathrm{a}$ & $1.8 \mathrm{a}$ \\
Cantaloupe cv. Magnum .45 & $2.6 \mathrm{a}$ & $1.4 \mathrm{a}$ & $2.4 \mathrm{a}$ \\
Cantaloupe cv. Top Net & $2.6 \mathrm{a}$ & $1.6 \mathrm{a}$ & $2.2 \mathrm{a}$ \\
Squash cv. Super Set & $1.5 \mathrm{~b}$ & $0.0^{\mathrm{z}}$ & $0.5 \mathrm{~b}$ \\
\hline
\end{tabular}

y $0=$ no symptoms; $1=$ slight or limited area of discoloration; $2=$ general discoloration, one or two lesions; $3=$ general discoloration, rot of some tissues; and $4=$ rot of entire tap and feeder roots. Means in each column followed by the same letter are not significantly different $(P \leq 0.05)$ according to Fisher's least significant difference test. Values are means of eight observations in two trials.

${ }^{\mathrm{z}}$ No disease observed, not included in analysis of variance. 
from plants, nor were typical symptoms ever seen in that area. It is possible that $M$. cannonballus is persisting saprophytically in this area or that the recovered spores were not those of $M$. cannonballus. Due to its thermophilic nature $(14,23), M$. cannonballus may be more active as a pathogen in southern California.

A. cucurbitacearum and Rhizopycnis vagum caused only slight root rot on melons in field microplots, but caused a more severe secondary root rot under greenhouse conditions. In contrast, symptoms caused by $M$. cannonballus were more severe in the field than in the greenhouse. This discrepancy in disease severity between the two types of experiments may be due to differences in inoculum potential, or interactions with environmental conditions (soil type, irrigation, temperature, and so on).

Although A. cucurbitacearum has been reported from California $(2,5)$, this is the first documentation of its frequent and widespread occurrence throughout the state. The observed resistance of summer squash (C. pepo) to A. cucurbitacearum adds to the list of known resistant cucurbits, which includes autumn squash $(C$.
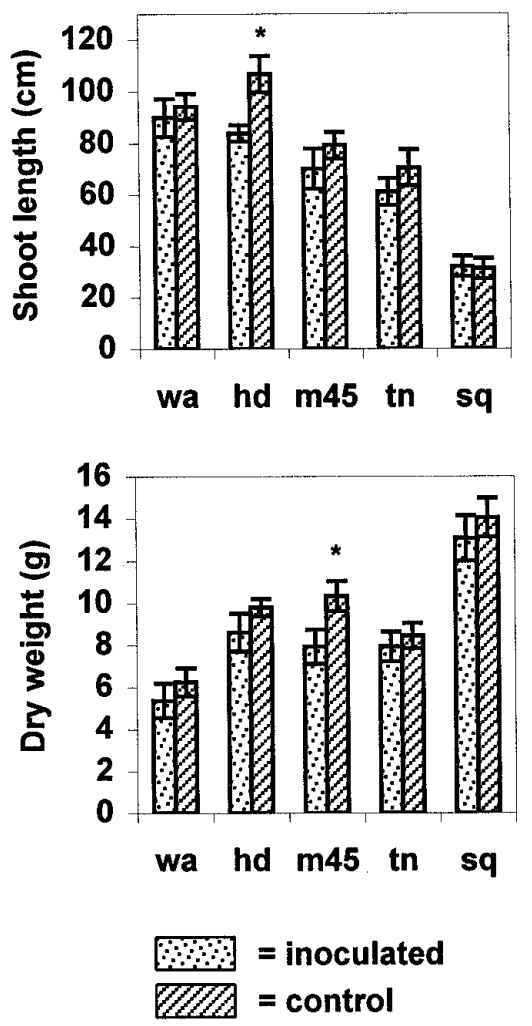

Fig. 3. Effect of Acremonium cucurbitacearum on shoot length and dry weight of greenhousegrown cucurbits. Abbreviations: wa $=$ watermelon cv. Crimson Sweet, hd = honeydew cv. Green Flesh, m45 = cantaloupe cv. Magnum .45 , th = cantaloupe $\mathrm{cv}$. Top Net, and $\mathrm{sq}=$ squash cv. Super Set. Bars indicate the standard error of the mean of eight observations in two trials. Asterisks indicate differences between adjacent treatments significant at $P \leq 0.05$. maxima, 4). Our results from the greenhouse studies confirm previous reports of the susceptibility of cantaloupe to $R$. vagum $(9,16)$. This is the first report of $R$. vagum in California.

Although root colonization by A. cucurbitacearum, $R$. vagum, and $M$. cannonballus may contribute to vine decline, there are likely to be other factors that determine whether a vine collapses or only sustains root damage and still produces a profitable yield. In our survey, plant pathogenic fungi were isolated from vines exhibiting root symptoms but with healthy foliage, suggesting that some root damage can be tolerated by the vine, at least under certain conditions. In Israel, it has been shown that heat stress and fruit load stress may be significant factors affecting vine decline of melons, in addition to root infection by fungi (19). The environmental factors that contribute to the disease in California need to be determined.

\section{ACKNOWLEDGMENTS}

We thank B. D. Bruton for sharing fungal cultures and helpful insights, and G. J. Holmes and J. G. Valencia for help in locating fields.
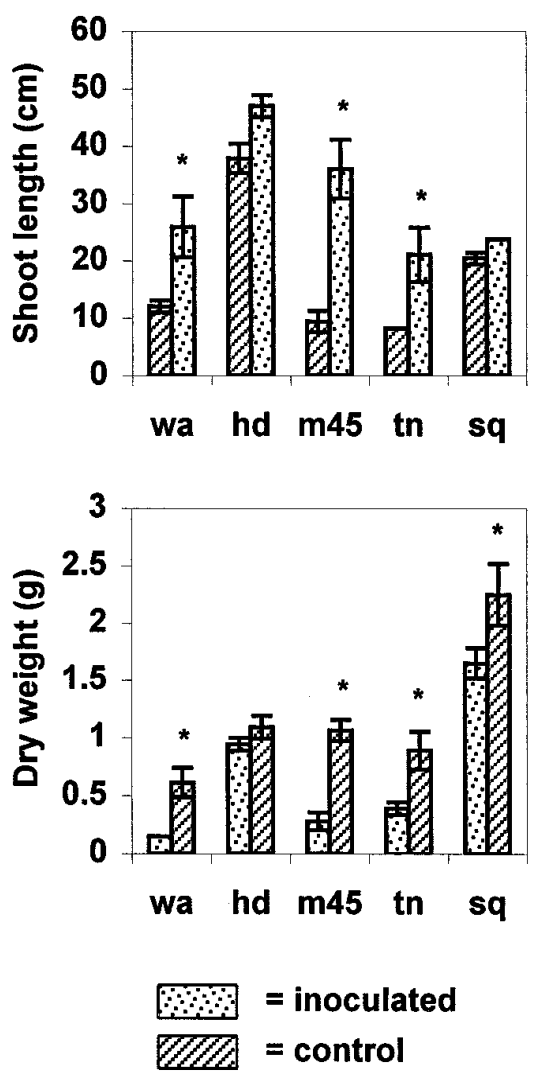

Fig. 4. Effect of Monosporascus cannonballus on shoot length and dry weight of greenhousegrown cucurbits. Abbreviations: wa $=$ watermelon cv. Crimson Sweet, hd = honeydew cv. Green Flesh, $\mathrm{m} 45$ = cantaloupe cv. Magnum .45 , $\mathrm{tn}=$ cantaloupe $\mathrm{cv}$. Top Net, and $\mathrm{sq}=$ squash cv. Super Set. Bars indicate the standard error of the mean of four observations in one trial. Asterisks indicate differences between adjacent treatments significant at $P \leq 0.05$.
LITERATURE CITED

1. Adams, G. C., Jr., Gubler, W. D., and Grogan, R. G. 1987. Seedling disease of muskmelon and mixed melons in California caused by Fusarium equiseti. Plant Dis. 71:370-374.

2. Alfaro-García, A., Armengol, J., Bruton, B. D., Gams, W., García-Jiménez, J., and Martínez-Ferrer, G. 1996. The taxonomic position of the causal agent of Acremonium collapse of muskmelon. Mycologia 88:804808.

3. Amann, A. B. 1989. The etiology of Pythium sudden wilt of cantaloupe in the Imperial Valley of California. MS thesis. University of California, Davis.

4. Armengol, J., Sanz, E., Martínez-Ferrer, G., Sales, R., Bruton, B. D., and García-Jiménez, J. 1998. Host range of Acremonium cucurbitacearum, cause of Acremonium collapse of muskmelon. Plant Pathol. 47:29-35.

5. Bruton, B. D., Davis, R. M., and Gordon, T. R. 1995. Occurrence of Acremonium sp. and Monosporascus cannonballus in the major cantaloupe and watermelon growing areas of California. (Note) Plant Dis. 79:754.

6. Bruton, B. D., Gordon, T. R., and Davis, R. M. 1995. Optimum CFU concentrations for testing pathogenicity of California cucurbit isolates of Monosporascus cannonballus and an Acremonium sp. (Abstr.) Phytopathology 85:1119.

7. California Agricultural Statistics Service. 1999. Calif. Veg. Rev. 20.

8. Champaco, E. R., Martyn, R. D., Barnes, L. W., Miller, M. E., Amador, J. M., and Perez, A. 1988. Root rot, a new disease of muskmelon in South Texas. (Abstr.) Phytopathology 78:626.

9. Farr, D. F., Miller, M. E., and Bruton, B. D. 1998. Rhizopycnis vagum gen. et sp. nov., a new coelomycetous fungus from roots of melons and sugarcane. Mycologia 90:290296.

10. García-Jiménez, J., Veláquez, M. T., Jordá, C., and Alfaro-García, A. 1994. Acremonium species as the causal agent of muskmelon collapse in Spain. Plant Dis. 78:416-419.

11. Gordon, T. R., Okamoto, D., and Jacobson, D. J. 1989. Colonization of muskmelon and nonsusceptible crops by Fusarium oxysporum f. sp. melonis and other species of Fusarium. Phytopathology 79:1095-1100.

12. Gottlieb, M., and Butler, K. D. 1939. A Pythium root rot of cucurbits. Phytopathology 29:624-628.

13. Gubler, W. D., and Grogan, R. G. 1982. Factors affecting sudden wilt of melon in California. (Abstr.) Phytopathology 72:986.

14. Martyn, R. D., and Miller, M. E. 1996. Monosporascus root rot and vine decline: an emerging disease of melons worldwide. Plant Dis. 80:716-725.

15. Mertely, J. C., Martyn, R. D., Miller, M. E., and Bruton, B. D. 1991. Role of Monosporascus cannonballus and other fungi in a root rot/vine decline of muskmelon. Plant Dis. 75:1133-1137.

16. Miller, M. E., Bruton, B. D., and Farr, D. F. 1996. Association of a Stagonospora-like fungus on roots of melons exhibiting vine decline symptoms. (Abstr.) Phytopathology 86:S3.

17. Nelson, P. E., Tousson, T. A., and Marasas, W. F. O. 1983. Fusarium Species: An Illustrated Manual for Identification. The Pennsylvania State University Press, University Park.

18. Newman, E. I. 1966. A method of estimating the total length of root in a sample. J. Appl. Ecol. 3:139-145.

19. Pivonia, S., Cohen, R., Kafkafi, U., Ben Ze'ev, I. S., and Katan, J. 1997. Sudden wilt of melons in southern Israel: Fungal agents and relationship with plant development. 
Plant Dis. 81:1264-1268.

20. Pollack, F. G., and Uecker, F. A. 1974. Monosporascus cannonballus, an unusual Ascomycete in cantaloupe roots. Mycologia 66:346349.

21. Puhalla, J. E. 1984. A visual indicator of heterokaryosis in Fusarium oxysporum from celery. Can. J. Bot. 62:540-545.

22. Risser, G., and Laugie, M. 1968. Mise en evidence de la sensibilite de divers cultivars de melon (Cucumis melo L.) a Pyrenochaeta sp agent de la "maladie des racines liegeuses" de la tomate. Ann. Amelior. Plantes 18:75-80.

23. Stanghellini, M. E., Kim, D. H., and Rasmussen, S. L. 1996. Ascospores of Monosporascus cannonballus: Germination and distri-

bution in cultivated and desert soils in Arizona. Phytopathology 86:509-514.

24. Stanghellini, M. E., and Rasmussen, S. L. 1992. A quantitative method for the recovery of ascospores of Monosporascus cannonballus from field soil. (Abstr.) Phytopathology $82: 1115$.

25. Troutman, J. L., and Matejka, J. C. 1970 Three fungi associated with cantaloupe root in Arizona. (Abstr.) Phytopathology 60:1317.

26. Ward, K. J., Klepper, B., Rickman, R. W., and Allmaras, R. R. 1978. Quantitative estimation of living wheat-root lengths in soil cores. Agron. J. 70:675-677. 